\title{
Blood eosinophils and IgE levels among umbilical cord transplantation recipients with food allergies
}

This article was published in the following Dove Press journal:

Journal of Asthma and Allergy

\section{Amrita Dosanjh' \\ Kaitlyn P Lew ${ }^{2}$}

'Pediatric Respiratory, San Diego, CA, USA; ${ }^{2}$ Brown University, Providence,

RI, USA
Correspondence: Amrita Dosanjh Pediatric Respiratory, San Diego, CA, USA

Tel + I 8584426146

Email pulmdI@gmail.com

\begin{abstract}
The use of immunosuppressive treatments and their related gastrointestinal adverse effects have been implicated in the development of food allergic responses following transplantation. There is limited information on the pathogenesis of the food allergic immune response among umbilical cord transplantation recipients. This study was conducted to identify a cohort of food allergic umbilical cord recipients in the literature. The literature was searched to systematically identify this cohort. Criteria for inclusion included umbilical cord transplantation, food allergic response, and reported laboratory data. Analysis of the laboratory data using the Pearson method revealed that there was a moderate negative correlation with a coefficient of $r=-0.7016$ and $r^{2}=-0.49$ between peripheral eosinophilia and serum immunoglobulin E (IgE) levels. Future studies on a larger population are needed, but this study may help to elucidate possible cellular mechanisms involved in this response.

Keywords: GVHD, tacrolimus, cord blood, stem cell
\end{abstract}

\section{Introduction}

The exposure adjusted incidence rate of gastrointestinal disorders among children being treated with tacrolimus after solid organ transplantation is higher than those receiving cyclosporine. Tacrolimus and cyclosporine are immunosuppressive drugs designed to prevent organ rejections. In one study of 105 children receiving tacrolimus and 39 children receiving cyclosporine following renal transplantation, the incidence rates for gastrointestinal disorders were 0.128 and 0.056 respectively. ${ }^{1}$ Among the gastrointestinal disorders identified, eosinophilic gastrointestinal disease (EGID) and food allergies manifesting with gastrointestinal (GI) symptoms have been studied. While the use of tacrolimus is considered a risk factor for the development of GI symptoms following transplantation, another study of 352 pediatric liver transplantation recipients showed that 30 (8.5\%) children developed food allergy and/or EGID. ${ }^{2}$ The clinical manifestations included GI symptoms $(53 \%)$ or urticarial/angioedema $(40 \%)$. Of the 15 children with food allergies who underwent endoscopy, 11 had eosinophilic infiltrates in multiple areas of the GI tract. Those with a combination of higher blood eosinophilia and prior history of allergic disease were at greater risk. ${ }^{2}$ Another literature study described an association between graft-versus-host disease (GVHD) and food allergies. Those patients who had received tacrolimus were more likely to develop food allergies $(16.1 \%$ vs $3.2 \%, p=0.015){ }^{3}$ There is a focus on tacrolimus because this is a commonly used transplant immunosuppressive medication, and thus one possible such effect may be considered among this specific cohort. We did not find any other literature relevant regarding other medications. 
The goals of this study were 1) to identify cases of post umbilical cord stem cell transplant related food allergy and 2) to analyze the relationship between the total serum $\operatorname{IgE}$ and peripheral eosinophil counts.

\section{Materials and methods}

\section{Literature search}

The terms "cord blood", "transplantation", "stem cell", and "food allergy" were used to identify possible cases for further investigation. The online PubMed and Medline databases were searched to identify articles, which described case-related laboratory data.

\section{Case review}

The articles were then searched for available food allergy cases among umbilical cord stem cell transplantation recipients. Clinical data per case was then extracted to include total serum IgE level $(\mathrm{IU} / \mathrm{ml})$ and peripheral blood eosinophil count (x 10/L).

Statistical Analysis was completed to calculate the Pearson Correlation Coefficient, or $r$ value. The $r^{2}$ value and mean values were also calculated.

Declaration of animal and human studies: not applicable, since this is a literature review.

\section{Results}

There were a total of 6 food allergy cord blood transplantation cases available with both datasets reported. ${ }^{4,5}$ There were three pediatric cases with no report of either value, and one report with the total serum IgE value and the term elevated peripheral eosinophil counts. These reports were therefore not included for analysis. ${ }^{3,6}$

The results indicated that the mean peripheral eosinophil count was 800.82 (range $0.92-1,648$ ) x $10^{-9} / \mathrm{L}$. There was only one patient with a serum IgE level of greater than $1,000 \mathrm{IU} / \mathrm{ml}$ and one patient with a total serum $\operatorname{IgE}$ level greater than $300 \mathrm{IU} / \mathrm{ml}$. These results are summarized in (Table 1).

Based on the analysis of correlation using the Pearson Method, there was a moderate negative correlation with a coefficient of $r=-0.7016$ and $r^{2}=-0.49$.

\section{Discussion}

This study was conducted to investigate the relationship between total peripheral eosinophil counts and serum IgE levels among patients receiving umbilical cord stem cell transplantation, and who have subsequently developed
Table I A summary of laboratory and clinical data. The peripheral eosinophil total counts/L and the total IgE serum values are shown

\begin{tabular}{|l|l|l|l|l|}
\hline $\begin{array}{l}\text { Peripheral } \\
\text { Eosinophil } x \\
\text { I0 e9/L }\end{array}$ & $\begin{array}{l}\text { Total } \\
\text { IgE } \\
\text { IU/ml }\end{array}$ & Age & $\begin{array}{l}\text { GVHD } \\
\text { Acute }\end{array}$ & $\begin{array}{l}\text { Tacrolimus } \\
\text { treatment/ } \\
\text { prophylaxis }\end{array}$ \\
\hline 766 & $<25$ & $3 \mathrm{y}$ & + & + \\
$\mathrm{I}, 648$ & 35 & $8 \mathrm{mo}$ & + & + \\
447 & 86 & $2 \mathrm{y}$ & + & + \\
$\mathrm{I}, 078$ & 26 & $\mathrm{I} y$ & + & + \\
865 & 468 & $6 \mathrm{mo}$ & + & + \\
0.92 & $\mathrm{I}, 300$ & $55 \mathrm{y}$ & + & + \\
\hline
\end{tabular}

Abbreviations: EGID, eosinophilic gastrointestinal disease; Gl, gastrointestinal; GVHD, graft-versus-host disease.

food specific IgE allergic responses. The findings indicate a moderate negative correlation between peripheral eosinophil counts and total serum IgE. The process of Th2 driven clinical responses may involve activation of eosinophils and eosinophil-based GI disease based on this study and the work of the other authors. While all the patients had specific IgE responses to food allergens, patients did not necessarily have elevated total IgE levels. In fact, lower total serum IgE levels were moderately and negatively correlated with peripheral eosinophil counts. Unfortunately, the literature in this area of clinical and investigational interest is limited. This study contributes further analysis and perspective regarding the possible mechanisms associated with food allergic responses among transplanted populations.

One frequently cited mechanism involves gut permeability and induction of $\mathrm{Th} 2$ inflammatory responses, as a result of the use of tacrolimus. The use of tacrolimus as a risk factor has been identified and among 10 of 12 patients studied, the drug was used prior to development of food allergy. ${ }^{3}$ In the same study, all cases were also diagnosed with GVHD.

The role of GVHD in the development of food allergy has been identified and further study is needed to elucidate the molecular mechanisms. Among liver transplant recipients, the liver allograft plays a role in presentation of gut-derived antigens to naïve $T$ cells by liver antigen presenting cells. Among patients with GVHD, the gut derived antigens may increase and lead to Th2 food allergic responses rather than tolerance. ${ }^{7}$ Food allergy and EGID has been shown to occur among liver transplantation recipients. In one study of 15 food allergic children undergoing endoscopy following liver transplantation, 11 had eosinophilic infiltrates in multiple segments of the esophagus alone or in combination with other bowel segments. ${ }^{2}$ 
This and other studies are needed to further study the pathways of allograft related initiation of $\mathrm{Th} 2$ responses to food allergens.

\section{Acknowledgment}

The authors would like to thank Rady Health Sciences Medical Librarian Services for their expertise and assistance in this report.

\section{Disclosure}

The authors report no conflicts of interest in this work.

\section{References}

1. Lancia P, Aurich B, Ha P, Maisin A, Baudouin V, Jacqz-Aigrain E. Adverse events under tacrolimus and cyclosporine in the first 3 years post-renal transplantation in children. Clin Drug Invest. 2018;38 (2):157-171. doi:10.1007/s40261-017-0594-0
2. Wisniewski J, Lieberman J, Nowak-Wegrzyn A, et al. De novo food sensitization and eosinophilic gastrointestinal disease in children post-liver transplantation. Clin Transplant. 2012;26(4):E365-E371. doi:10.1111/j.1399-0012.2012.01670.x

3. Hernandez-Ojeda A, Rojas N, Barriga F, Wietstruck A, Morales P, Borzutsky A. Incidence and risk factors of food allergy after umbilical cord blood transplantation in children. J Allergy Clin Practice. 2017;5(6):1789-1791. doi:10.1016/j.jaip.2017.04.034

4. Mori T, Kata J, Sakurai M, et al. New-onset food allergy following cord blood transplantation in adult patients. Bone Marrow Transplant. 2016;51:295-296. doi:10.1038/bmt.2015.243

5. Sakashita K, Nakazawa Y, Yanagisawa R, et al. Food allergy after cord blood transplantation in children. Br J Haematol. 2012;158 (5):662-676. doi:10.1111/j.1365-2141.2012.09204.x

6. Inoue Y, Ochiai H, Hishiki T, Shimojo N, Shimojo H, Kohno Y. Food allergy after cord blood stem cell transplantation with tacrolimus therapy in two patients who developed veno-occlusive disease. Allergol Int. 2012;61(3):497-499. doi:10.2332/allergolint.11-OA0306

7. Feliu J, Clay J, Raj K, et al. Transplant-acquired food allergy following cord blood stem cell transplantation in two adult patients with haematological malignancies. $\mathrm{Br} J$ Haematol. 2014;167:418-438. doi:10.1111/bjh. 12992

\section{Publish your work in this journal}

The Journal of Asthma and Allergy is an international, peer-reviewed open-access journal publishing original research, reports, editorials and commentaries on the following topics: Asthma; Pulmonary physiology; Asthma related clinical health; Clinical immunology and the immunological basis of disease; Pharmacological interventions and new therapies. The manuscript management system is completely online and includes a very quick and fair peer-review system, which is all easy to use. Visit http://www.dovepress.com/testimonials.php to read real quotes from published authors. 